method be devised for a due supply of genuine remedies, it would be far better to trust the cure of disease to the healing hand of nature, than to disturb her operations by villanous compounds, miscalled medicines.

\section{HOUSE OF COMMONS.}

VACCINATION ACT AMENDMENT BILL.

Thursday, May 20.

Mr. Fox Maule moved the original clauses in a committee of the whole house.

Mr. F. French moved the addition of the following clauses :-

" (Guardians and overseers to appoint medical practitioners to vaccinate, at an annual stipend.)

" And be it further declared and enacted, That it shall be lawful for the gnardians of every parish or union in England and Ireland, and the overseers of every parish or union in which relief for the poor shall not be administered by guardians, and they are hereby directed, to employ any legally qualified medical practitioner or practitioners for the vaccination of persons resident in such parishes or unions respectively; and to appoint and pay such reasonable annual stipend or remuneration for the same as to the said guardians or overseers shall seem fit, and to defray the same out of any rates or monies which may come into their hands respectively for the relief of the poor, anything in any other act contained to the contrary notwithstanding.

"(Who shall be deemed a competent medical practitioner.)

" And be it further declared and enacted, That no person shall be deemed to be a legally qualified or competent medical practitioner, within the meaning of the said recited act or this act, who shall not be duly authorised by some university or college, or other public body, having authority in that behalf, to practise medicine or surgery."

He said, the object of the first clause was to enable the guardians to employ medical men to vaccinate the poor without subjecting those gentlemen to the degradation of the contract and tender system - the adoption of which being, according to the act, compulsory, great offence had been thereby given to the medical profession, and in many instances, as for example, in Ennis, Wexford, Fermoy, and Kinsale \&c. unions, the act was inoperative, from the dislike of medical men to carry it into effect ; this dislike would be removed by enabling guardians, where necessary, to employ vaccinators, at a small annual stipend, when it might be necessary so to do-an option which might be conceded without imposing any additional expense-probably at a less expense than under the present plan; and the guardians and commissioners would always have it in their power to demand returns, and thus to check and control the medical men. As to the unsatisfactory nature of the present plan there was abundant evidence in the number of petitions for a change, which had been presented. (One of these from the College of Surgeons in Ireland, the honourable member here read.) With regard to the second clause, its object was to define, in a general way, the meaning of the words " medical practitioner." In the act, two descriptions are given of the persons who should be employed as vaccinators. In the first clause it is enacted, that in England and Wales, the medical practitioner should be "legally qualified," while in the sixth clause, which relates to Ireland, it is enacted that the practitioner should be " competent," a discrepancy which gave rise to many inconveniences. In this proposed clause he had adopted a definition already introduced in the Factories Bill, which was sufficiently loose to admit every person having any legal claim to be considered as a medical practitioner.

Mr. F. Maule regretted he could not agree to the introduction of these clauses, as he had brought forward the bill under a pledge that it should only go the length of remedying two defects in the original act. 'The proposed clauses would alter the principle of remuneration, and would also open up the difficult question of medical qualification.

Mr. Wakley trusted the Hon. Under Secretary would not agree to the proposed clauses. The question had already been fully discussed, and the principle adopted that the payments to medical men employed as vaccinators under the act should be in proportion to the amount of labour done. It must be recollected that inoculation with smallpox had been made penal, and it was therefore necessary that it should be made the interest, as well as the duty, of medical men to seek out cases for vaccination, which they would not do, if, as was now proposed, their remuneration should be made irrespective of the number of persons whom they might successfully vaccinate. He would, therefore, oppose the introduction of the clauses.

Mr. Warburton also opposed the introduction of the clauses, which were negatived without a division.

The bill was then committed.

\section{ROYAL MEDICAL AND CHIRURGICAL SOCIETY.}

Tuesday, May 11, 1841.

Dr. Williamí, President.

READ, COLICA PICTONUM, TREATED WITH WARM WATER. BY JOHN WILSON, M. D., PHYSICIAN TO THE MIDDLESEX HOSPITAL.

In this paper the author, after referring to the complicated treatment of the disease pursued at the hospital of La Charité, proposes to illustrate two of the remedies there used in combination, namely, enemata and hot-baths.

In six cases of colica Pictonum, some of them of much severity and complicated with paralysis, $\mathbf{D r}$. Wilson has employed enemata, administered in the hot-bath, in one case by the patient himself, and consisting of the water of the bath. The effect of this combination has been very successful, both in regard to the symptoms of pain and constipation, and to the paralysis, where that existed. In the course of his statements, the author notices the presence of looseness of the gums, blueness of their edges, and a fotor like that of mercury, where 
none had been taken; and informs us that he has noticed this latter circumstance in other cases of colica pictonum. He next details a case of constipation not attributable to lead, in which the above remedies had proved equally successful.

In some of the above cases this treatment is used alone; in others it is followed up by doses of pil. saponis cum opio, of oleum ricinum with tincture of opium, or with a solution of sulphate of magnesia, with carbonate of magnesia in mint water.

READ, RESULTS OF AMPUTATIONS AT UNIVERSITY COLLEGE HOSPITAL, BY JOHN P. POTTER, ESQ. COMMUNICATED BY MR. IISTON.

Feeling that the only chance of arriving at any safe and satisfactory conclusions in medical statistics depends on the number and accuracy of reports and cases from which such conclusions are to be drawn, the author has examined the report-books of University College Hospital, and collected all the cases in which amputation has been performed since the opening of the institution, on the shoulders, arm, forearm, wrist, thigh, and leg. These he has arranged in the form of tables, and has subjoined a few remarks on the mode of amputation which has been adopted, and the method of dressing which has been observed.

The number of cases from the last day of June, 1836 , to the termination of the year 1840 , has been 66 ; and of these, 56 proved successful, whilst 10 have been attended with fatal results, at a variable period of time after the performance of the operation.

Of the 66 cases, 11 were subjected to amputation on account of severe compound fractures, and other injuries, within twenty-four hours after the occurrence of the accidents. Of these, three terminated fatally in seven, eleven, and forty-eight days respectively. In the first of the three, both legs were amputated. The remaining seven cases recovered in periods varying from twenty-three to one hundred and forty-six days.

In the remaining 56 cases, amputation was performed on account of long standing disease, or for injuries, in which an attempt had been made to save the limbs. Of this number only seven died. The statistical part of the paper is followed by observations at some length on the mode of amputation, and the system of dressing the stumps pursued at the hospital.

READ ALSO, A CASE OF MALPOSITION OF THE KIDNEYS, AND ABSENCE OF THE VAGINA, UTERUS, AND FALLOPIAN TUBES; BY R. BOYD, RESIDENT PHYSICIAN TO THE ST. MARYLEBONE INFIRMARY, LECTURER ON MEDICINE. COMMUNICATED BY MR. PERRY

The patient was 72 years of age, and died lately in the workhouse of St. Marylebone, nothing being known of her previous history, beyond the fact that she had been married, and had not lived on amicable terms with her husband.

On dissection, the right kidney was found in the right iliac fossa, below the cœcum, and received its artery from the right iliac, close to the aorta. The left kidney was in the pelvis, resting on the sacrum, and the origin of the pyriform muscle. An artery which arose from the aorta at its bifurcation, entered its upper end ; another of larger size, penetrating the gland in the usual situation, being derived from the internal iliac.

Notwithstanding the unusual malposition of the kidneys, the renal capsules were in their normal situation-a fact, which appears to favour the views of Mr. Gulliver as to the function of the latter organs. From that gentleman's observations, it would appear that the renal capsules secrete a peculiar matter, which may be found in the veins, from which it would follow that these organs are glands, to which the veins serve as ducts.

The uterus and Fallopian tubes were entirely wanting, and the vagina was represented by a culde-sac half an inch in depth. The right ovary was healthy, but the left was converted into a fibrous body, of an irregular globular shape. The paper was illustrated by a preparation and drawing of the genito-urinary organs.

\section{ACADEMY OF SCIENCES.}

Paris, May 17.

\section{EXTIRPATION OF THE SUB-MAXILLARY GLAND.}

BARON LARREY read a report on this case, which was communicated by $M$. Colson. The patient had been affected with cancer of the lower lip, accompanied with a large tumor under the jaw, which was supposed to be a lymphatic gland. On attempting to remove it, however, it was found to be the sub-maxillary gland, changed into an encephaloid mass. The operator was compelled to divide the lingual branch of the fifth nerve, and the submental artery. The patient recovered.

\section{NERVES OF THE UTERUS.}

M. Jobert read a memoir on the nerves of the uterus. The author appears to have been entirely ignorant of the work of our countryman, Dr. Robert Lee, on the same subject. Amongst other facts, M. Jobert notices the total absence of nerves in the projecting portion of the neck of the uterus, and hence concludes, that it is devoid of sensation, an opinion quite opposed to that of most practitioners. (In Dr. Lee's plates, the neck of the uterus is seen furnished with numerous nerves). Having laid down this fact, $M$. Jobert deduces from it several conclusions relative to the treatment of diseases of the cervix uteri. He cites several cases, to show that if we take care to protect the adjacent tissues, we may emplow the actual cautery to the neck of the uterus without exciting any pain. M. Jobert affirms that the nerves of the uterus never undergo any change at different periods of life, and points out the causes which have led some anatomists to believe, erroneously, that they become enlarged during uterogestation. In support of this opinion, M. Jobert presented several plates of the nerves in young females, in old women, and in females at the different stages of pregnancy, and infers from them that in these different states the uterine nerves are constantly the same. 